\title{
International Migration of Labor, Efficiency Wages, and Monetary Policies
}

\author{
Akira Shimada \\ Nagasaki University
}

\begin{abstract}
Assuming a symmetric two-country economy with labor migration and efficiency wages, we investigate which of the two regimes, non-cooperation or intergovernment cooperation, is advantageous. We show that not only the utility of the policy authority but also that of the workers is higher under inter-government cooperation than under non-cooperation, provided that migration flows are sufficiently sensitive to changes in real-consumption wage differentials. Our result is in contrast to the one derived by Agiomirgianakis (1998); according to him, in a two-country economy with labor migration and labor unions, only the policy authority can attain the higher utility under inter-government cooperation.
\end{abstract}

- JEL classification: F42, F22, J41, F41

- Keywords: Monetary policy games, International migration of labor, Efficiency wages, Two-country economy

\section{Introduction}

This paper is concerned with monetary policy games in a two-country economy that is characterized by international labor migration and efficiency wages, and it attempts to show that inter-government cooperation in the monetary field may prove to be advantageous not only to the policy authority but also to the workers.

International monetary cooperation has become one of the crucial issues for many governments since they have to take into consideration policy inter-

\footnotetext{
*Corresponding address: Akira Shimada, Faculty of Economics, Nagasaki University, 4-2-1, Katafuchi, Nagasaki City, 852-8506, Japan. Tel.: +81 95820 6353. E-mail: chapislz@yahoo.com. 
dependence among countries, which has increased not only due to the growing amount of international trade of goods and international flow of financial capital but also due to the growing mobility of labor across borders.

Needless to say, the question regarding whether or not the policy authorities should cooperate in the monetary field is not new. Several authors, including Hamada (1976) and Rogoff (1985) as early contributors, have analyzed this problem. However, various studies on this issue have not paid sufficient attention to the mobility of labor.

Agiomirgianakis (1998) analyzed this problem by utilizing a symmetric twocountry macroeconomic model. ${ }^{1}$ His analysis was different from the previous analyses on this issue, since he assumed the labor migration between two countries due to the differences in real-consumption wages (nominal wages divided by the consumer price index).

He demonstrated that under the possibility of international migration, intergovernment cooperation may prove to be advantageous. In particular, he revealed that the utility of the policy authority is likely to be higher under inter-government cooperation than under non-cooperation, whereas the utility of workers does not differ across regimes.

In order to obtain this result, he modeled labor markets by assuming the existence of labor unions. Nominal wages and employment are determined through negotiations between the labor union and the firm in the same manner as is assumed in the monopoly union model (Dunlop, 1944; Oswald, 1985).

However, in reality, labor unions are not always influential in the determination of nominal wages and employment. Even so, labor unions are exogenous factors. Their existence and objectives can be derived from the workers' rational behavior.

Therefore, in this paper, a labor market is modeled by efficiency wages instead of labor unions, and embedded into a symmetric two-country macroeconomic model with labor migration in order to infer as to which of the two regimes, noncooperation or inter-government cooperation in the monetary field, is advantageous to the policy authority and to the workers. ${ }^{2}$

This paper demonstrates that not only the utility of the policy authority but also

\footnotetext{
${ }^{1}$ Although there are various other approaches to analyze international migration of labor, it is most appropriate to utilize open macroeconomic models since the effects of labor migration are not limited to those on the specific markets belonging to labor-sending and labor-receiving countries but extend to all sectors of these countries' economies. Accordingly, several studies (Agiomirgianakis, 1996, 1999, 2000; Agiomirgianakis and Zervoyianni, 2001; Shimada, 2003) utilized either the two-country or small open economic models to investigate the consequences of labor migration.
} 
that of the workers is higher in the inter-government cooperative regime than in the non-cooperative regime, provided that migration flows are sufficiently sensitive to the changes in real-consumption wage differentials. In other words, in a symmetric two-country economy with labor migration and efficiency wages, inter-government cooperation may prove to be advantageous to the policy authority and to the workers.

The result that inter-government cooperation may prove to be advantageous to the policy authority can be explained as follows: Since, in the inter-government cooperative regime, policy authorities take into consideration the fact that the influence of a domestic monetary expansion for reducing unemployment via an induced fall in the effective labor force will be offset by an equal expansion abroad, they do not increase the money stocks in order to reduce unemployment, even if the sensitivity of migration flows is large and the domestic monetary expansion seems to be effective in reducing unemployment. This suggests that money stocks are independent of the sensitivity of migration flows, thereby making unemployment and the consumer price index independent of the sensitivity of migration flows in the inter-government cooperative regime. On the other hand, in the noncooperative regime, policy authorities do not consider the fact that the influence of a country's monetary expansion will be offset by another country's monetary expansion, and thus they unilaterally increase the money stocks in an attempt to reduce unemployment through the reduction in the effective labor force. This suggests that, in contrast to the inter-government cooperative regime, the money stocks in the non-cooperative regime depend on the sensitivity of migration flows, and they increase with increases in the sensitivity of migration flows. Consequently, in comparison to the inter-government regime, larger money stocks are observed in the non-cooperative regime for the sufficiently large sensitivity of migration flows. The larger money stocks under the non-cooperative regime reduce unemployment, which leads to a higher utility for the policy authority. On the hand, they lead to an increase in the consumer price index, which makes the utility for the policy authority lower. In case of sufficiently large sensitivity of migration flows, the latter negative effects outweigh the former positive effects, suggesting lower utility for the policy authority in the non-cooperative regime than in the inter-government cooperative regime. Therefore, inter-government cooperation is advantageous to the policy authority in case of the

\footnotetext{
${ }^{2}$ Assuming a dual labor market with efficiency wages, Carter (1999) analyzed the problem of illegal migration, and Müller (2003) investigated the effects of migration on a small open economy. Although their studies dealt with international migration under the assumption of efficiency wages, they did not utilize open macroeconomic models.
} 
sufficiently large sensitivity of migration flows.

The result that inter-government cooperation may also prove to be advantageous to the workers can be explained as follows: Since the utility of workers decreases with increases in the consumer price index, larger money stocks result in a lower utility for the workers under non-cooperation. On the other hand, although the consumer price index is also dependent on nominal wages, they take the same values in both the regimes. This is because the firm's wage-setting under the nonshirk condition and the workers' utility maximization do differ across regimes. Therefore, in case of sufficiently large sensitivity of migration flows, the utility for the workers in the non-cooperative regime is lower than that in the intergovernment cooperative regime, implying that inter-government cooperation is advantageous to the workers.

The result shown in this paper implies that inter-government cooperation in the monetary field appears to be preferable to non-cooperation in interdependent economies characterized by international migration and efficiency wages.

The result shown in this paper is in contrast to that shown by Agiomirgianakis (1998), since, in his model, inter-government cooperation may prove to be advantageous only to the policy authority. However, this paper's result is consistent with his argument that international migration of labor changes the nature of monetary policy games played by monetary authorities in interdependent economies.

The paper is organized as follows: Section II presents a symmetric two-country macroeconomic model with labor migration and efficiency wages. A firm in each country is assumed to be unable to detect shirking by workers perfectly and set nominal wages in order to prevent shirking. Sections III and IV deal with the noncooperative regime and the inter-government cooperative regime, respectively. Section V compares the utilities of the policy authority and the workers under the two regimes. Section VI includes the concluding comments.

\section{The Model}

A two-country economy is assumed - each country has a single non-competitive labor market and nominal wages are determined to prevent workers from shirking. Home and foreign countries are symmetric in their economic structures and are interdependent through international trade of goods and international migration of labor. In each country, there are workers, a firm, and a policy authority. Workers 
are not organized in labor unions.

Workers are assumed to migrate between home and foreign countries. Accordingly, effective labor force in the home country increases in comparison to its initial labor endowment, if workers in the foreign country migrate to the home country, and it decreases if workers in the home country migrate to the foreign country.

A firm in each country demands labor for producing a single kind of product. Since the firm cannot perfectly detect shirking by workers, it sets nominal wages in order to prevent shirking, treating workers' effort and the money stock as given. Workers, on the other hand, attempt to maximize their utilities by manipulating their effort, treating the firm's wage-setting and the money stock as given.

Each country's product is not only demanded in the same country but also in the other country and is exported there. The products of the home and foreign countries are imperfect substitutes.

It is assumed that each country has its own money market and that money is the only financial asset held by its residents.

The model is summarized by Equations (1)-(7). Structural equations in this paper are the same as those employed by Jensen (1993), Zervoyianni (1997), Agiomirgianakis (1998), and Shimada (2004). Variables are expressed in logs unless otherwise defined. Variables without the asterisk represent the home country and variables with the asterisk represent the foreign country.

$$
\begin{aligned}
& y=a l, y^{*}=a l^{*}, 0<a<1 . \\
& l=-\frac{1}{1-a}(w-p)+\frac{1}{1-a} \ln a, l^{*}=-\frac{1}{1-a}\left(w^{*}-p^{*}\right)+\frac{1}{1-a} \ln a . \\
& z \equiv e x+p^{*}-p . \\
& y-y^{*}=b z, b>0 . \\
& q \equiv p+c z, q^{*} \equiv p^{*}-c z, 0<c<1 / 2 . \\
& w_{c} \equiv w-q, w_{c}^{*} \equiv w^{*}-q^{*} . \\
& m=p+y, m^{*}=p^{*}+y^{*} .
\end{aligned}
$$


Equation (1) presents the production functions of the firms in the home and foreign countries, where $y$ represents output, $l$ represents the employment level, and $a$ is a constant not expressed in the log. Equation (2) presents the labor demand functions of the firms in the home and foreign countries, where $w$ represents nominal wages and $p$ represents the product price. They are derived from profit maximization of the firm in each country. Equation (3) defines the real exchange rate $z$, where $e x$ is the nominal exchange rate (home currency price of foreign currency). Equation (4) presents the equilibrium condition of the trade balances of the home and foreign countries, where $b$ is a constant not expressed in the log. The effects of the real exchange rates on the trade balance are assumed to be stronger than those of the difference in the national product of the two countries on the trade balance, so that $b$ is greater than $1 .^{3}$ We define the home (foreign) country's consumer price index $q\left(q^{*}\right)$ as a weighted average of the price of the home (foreign) country's product and the price of the foreign (home) country's product in term of the home (foreign) currency, giving rise to Equation (5), where $c$ is a constant not expressed in the log. ${ }^{4}$ Home and foreign countries' real-consumption wages $w_{c}$ and $w_{c}^{*}$ are given by Equation (6). Equation (7) presents the equilibrium conditions of the money markets in the home and foreign countries, where $m$ denotes the money stock. The policy authorities manipulate the money stocks.

An assumption is made in keeping with Agiomirgianakis (1998) that workers migrate between the two countries due to real-consumption wages differentials. For example, if the real-consumption wages in the home country are higher than those in the foreign country, then workers native to the foreign country migrate to the home country by $d\left(w_{c}-w_{c}^{*}\right)$, where $d$, which is a positive constant not expressed in the log, measures the sensitivity of migration flows to changes in the realconsumption wage differentials.

Assumptions on international migration of labor lead to the following definitions of the home country's effective labor force $l^{f}$ and the foreign country's effective labor force $l^{f^{*}}$ :

$$
l^{f} \equiv \bar{l}+d\left(w_{c}-w_{c}^{*}\right)
$$

\footnotetext{
${ }^{3}$ See Shimada (2004), footnote 3, for the economic interpretation of $b$.

${ }^{4}$ The home country's consumer price index is $P^{1-c}\left(E X P^{*}\right)^{c}$ and the foreign country's consumer price index is $P^{* 1-c}(P / E X)^{c}$ where $P \equiv \exp p, E X \equiv \exp e x$, and $P^{*} \equiv \exp p^{*}$. Residents of the home (foreign) country are assumed to have a preference for the goods produced in the home (foreign) country so that $0<c<1 / 2$.
} 


$$
l^{* f} \equiv \overline{l^{*}}+d\left(w_{c}^{*}-w_{c}\right), \bar{l}=\overline{l^{*}},
$$

where $\bar{l}$, which is a positive constant, denotes the domestic labor force in the absence of migration, i.e., the initial labor endowment.

Through appropriate substitutions, the model of Equations (1)-(7) can be solved for $l, l^{*}, y, y^{*}, p, p^{*}, z, q, q^{*}, w_{c}, w_{c}^{*}$ as functions of $w, w^{*}, m, m^{*}{ }^{5}$

$$
\begin{aligned}
& l=m-w+\ln a . \\
& l^{*}=m^{*}-w^{*}+\ln a . \\
& y=a(m-w)+a \ln a . \\
& y^{*}=a\left(m^{*}-w^{*}\right)+a \ln a . \\
& p=(1-a) m+a w-a \ln a . \\
& p^{*}=(1-a) m^{*}+a w^{*}-a \ln a . \\
& z=\frac{a}{b}\left\{m-w-\left(m^{*}-w^{*}\right)\right\} . \\
& q=\left(-a+\frac{a c}{b}\right)(m-w)+m-\frac{a c}{b}\left(m^{*}-w^{*}\right)-a \ln a . \\
& q^{*}=\left(-a+\frac{a c}{b}\right)\left(m^{*}-w^{*}\right)+m^{*}-\frac{a c}{b}(m-w)-a \ln a . \\
& w_{c}=\left(1-a+\frac{a c}{b}\right)(w-m)-\frac{a c}{b}\left(w^{*}-m^{*}\right)+a \ln a . \\
& w_{c}^{*}=\left(1-a+\frac{a c}{b}\right)\left(w^{*}-m^{*}\right)-\frac{a c}{b}(w-m)+a \ln a .
\end{aligned}
$$

This paper assumes that a firm in each country cannot perfectly observe whether the workers are shirking or not. Accordingly, as mentioned above, it sets nominal

${ }^{5}$ See Shimada (2004) pp. 91-92 for the economic interpretation of Equations (9.1)-(9.11). 
wages in a manner that prevents shirking (Shapiro and Stiglitz, 1984). Given nominal wages, employed workers in each country choose their effort level to maximize their expected lifetime utility.

Since workers are not organized in labor unions, employed workers have no concern for the number of workers employed. They are only interested in their wages. If a representative employed worker in each country does not shirk, his instantaneous utility can be measured by real-consumption wages less effort. On the other hand, if he shirks, his instantaneous utility is measured by realconsumption wages. However, in such a case, he is detected and fired at the probability $\rho, 0<\rho<1$. The probability $\rho$ is assumed to be the same for the two countries. In addition, some of the employed workers in each country might separate from jobs, even if they are not fired on the grounds of shirking. The separation rate, which is defined as the ratio of separations due to reasons other than shirking to the number of employed workers, is given by $\beta, 0 \leq \beta<1$. The separation rate $\beta$ is assumed to be the same for the two countries.

The expected lifetime utility of a representative employed shirker in the home country $V_{E}^{S}$ is,

$$
r V_{E}^{S}=w_{c}+(\beta+\rho)\left(V_{U^{-}}-V_{E}^{S}\right)
$$

where $r$ is the discount rate, which is assumed to be the same for two countries and $V_{U}$ is the expected lifetime utility of a representative unemployed worker in the home country. Equation (10) can be rewritten as,

$$
V_{E}^{S}=\frac{w_{c}+(\beta+\rho) V_{U}}{r+\beta+\rho} .
$$

On the other hand, the expected lifetime utility of a representative employed non-shirker in the home country $V_{E}^{N}$ is,

$$
r V_{E}^{S}=w_{c}-\ln e+\beta\left(V_{U}-V_{E}^{N}\right)
$$

where $e$, which is not expressed in the log, is effort of a representative employed non-shirker in the home country. Since employed non-shirkers exert a positive level of effort to some extent but cannot do so infinitely, the effort level of a representative employed non-shirker in the home and foreign countries is assumed to lie between its minimum $e^{\min }, e^{\min }>1$, and its maximum $e^{\max }$, i.e., $e^{\min } \leq e$, 
$e^{*} \leq e^{\max }$, where $e^{*}$ is effort of a representative employed non-shirker in the foreign country. Equation (11) can be rewritten as,

$$
V_{E}^{N}=\frac{w_{c}-\ln e+\beta V_{U}}{r+\beta}
$$

The employed workers in the home country may or may not shirk based on a comparison of $V_{E}^{N}$ and $V_{E}^{S}$. In order to prevent them from shirking, the firm in a home country has to set nominal wages that are sufficiently high to ensure $V_{E}^{N} \geq V_{E}^{S}$. However, because there is no reason for the firm in a home country to pay more than what is essential to eliminate shirking, it will set nominal wages such that $V_{E}^{N}=V_{E}^{S}\left(\equiv V_{E}\right)$. The following is obtained by substituting Equations (10') and (11') into this condition:

$$
w_{c}=r V_{U}+(r+\beta+\rho) \frac{\ln e}{\rho} .
$$

$V_{U}$ is, in turn, given by,

$$
r V_{U}=\ln \left(\overline{\frac{W}{Q}}\right)+\alpha\left(V_{E}-V_{U}\right)
$$

where $\bar{W}$ is the unemployment benefit in the home country, which is a constant not expressed in the $\log , Q \equiv \exp q$, and $\alpha, 0 \leq \alpha<1$, is the accession rate, the ratio of new hires in the home country to the number of workers unemployed in the home country. The foreign country is assumed to have the same accession rate as the one in the home country.

In order to simplify the analysis, this paper assumes that there are no separations or accessions in the home and foreign countries, i.e., $\beta=\alpha=0{ }^{6}$ This paper also assumes that $\bar{W}=\overline{W^{*}}=1$, where $\overline{W^{*}}$ is the unemployment benefit in the foreign country, which is not expressed in the log. Substituting these assumptions into Equation (12) and the equation for $V_{U}$, nominal wages in the home country become,

$$
w=\left(1+\frac{r}{\rho}\right) \ln e
$$

${ }^{6}$ Carter (1998) made a similar assumption. He assumed that workers in the high-wage sector do not quit nor are they separated from their job. 
Equation (13.1) shows that nominal wages in the home country increase with increases in effort of the employed workers in the home country and decrease with increases in the detection probability.

The expected lifetime utility of a representative employed worker in the home country under the non-shirk condition will take the form of,

$$
V_{E}=-\frac{q}{r}+\frac{\ln e}{\rho} .
$$

Equation (14.1) says that under the non-shirk condition, the expected lifetime utility of a representative employed worker in the home country decreases with increases in the home country's consumer price index. ${ }^{7}$

By the same argument, nominal wages in the foreign country and the expected lifetime utility of a representative employed worker in the foreign country are obtained under the non-shirk condition as follows:

$$
\begin{gathered}
w^{*}=\left(1+\frac{r}{\rho}\right) \ln e^{*}, \\
V_{E}^{*}=-\frac{q^{*}}{r}+\frac{\ln e^{*}}{\rho} .
\end{gathered}
$$

According to Equations (13.1), (13.2), (14.1), and (14.2), nominal wages and the expected lifetime utility of a representative employed worker are symmetric between the home and foreign countries.

The policy authority in each country attempts to attain full employment and the consumer price index target, which is assumed to be 0 . The utility function of the home country's policy authority $V_{P A}$ and the utility function of the foreign country's policy authority $V_{P A}^{*}$ are of the forms,

$$
\begin{gathered}
V_{P A}=-\left(l-l^{f}\right)^{2}-h q^{2}, h>0, \\
V_{P A}^{*}=-\left(l^{*}-l^{* f}\right)^{2}-h q^{* 2},
\end{gathered}
$$

where $h$, which is a constant not expressed in the log, reflects the relative weight

\footnotetext{
${ }^{7}$ This relation will be used to compare the utilities of the employed workers under two regimes in Section V.
} 
assigned by the policy authorities to employment as against the consumer price index. Equations (15.1) and (15.2) imply that policy authorities dislike deviations of actual levels of employment from the effective labor forces and changes in the consumer price index. These objectives are accomplished by the manipulation of the money stocks. ${ }^{8}$

\section{Non-Cooperation}

This section deals with the non-cooperative regime where the policy authorities in the home and foreign countries behave independently and the money stock, unemployment, and the consumer price index under non-cooperation are determined.

The employed workers in the home country will choose their effort in order to maximize the expected lifetime utility of a representative employed worker, treating $e^{*}, m$, and $m^{*}$ as given, i.e., they will solve,

$$
\max _{e}+\frac{q}{r}-\frac{\ln e}{\rho}, \quad \text { subject to }(9.8), \partial e^{*} / \partial e=0, \partial m^{\prime} \partial e=0 \text { and } \partial m^{*} / \partial e=0 .{ }^{9}
$$

This gives us the optimal effort level of the employed workers in the home country $\tilde{e}$.

$$
\tilde{e}=\left\{\begin{array}{l}
e^{\max }, \text { if }\left(1-a+a c^{\prime} b\right)(1+r / \rho)>1, \\
e^{\min }, \text { if }\left(1-a+a c^{\prime} b\right)(1+r / \rho)<1 .
\end{array}\right.
$$

Equation (16.1) suggests that if increases in the utility of the employed workers due to increases in their effort and in the real-consumption wages are larger (smaller) than decreases in the utility due to increases in their effort, they maximize their utility by exerting maximum (minimum) effort.

The optimal effort level of the employed workers in the foreign country $\tilde{e}^{*}$ is obtained in a similar manner.

${ }^{8}$ Policy authorities are assumed to be able to control the money stocks perfectly.

\footnotetext{
${ }^{9}$ As mentioned above, since the workers are not unionized, the utility of the employed workers does not depend on the number of the employed workers. Accordingly, the employed workers' objective function can be presented by the utility of a representative employed worker.
} 


$$
\tilde{e}^{*}=\left\{\begin{array}{l}
e^{\max }, \text { if }\left(1-a+a c^{\prime} b\right)(1+r / \rho)>1, \\
e^{\min }, \text { if }\left(1-a+a c^{\prime} b\right)(1+r / \rho)<1 .
\end{array}\right.
$$

Equations (16.1), (16.2), (13.1) and (13.2) suggest that the optimal effort level and nominal wages do not differ across countries.

The policy authority in the home country will set the money stock in order to maximize its utility, treating $e, e^{*}$, and $m^{*}$ as given, i.e., it will solve,

$\max _{m} V_{P A}$ subject to (9.1), (8.1), and (9.8), $\partial e^{\prime} \partial m=0, \partial e^{*} / \partial m=0, \quad$ and $\partial m^{*}=$ $\partial m=0 .{ }^{10}$

This gives us the condition,

$$
\left\{1+d\left(1-a+\frac{2 a c}{b}\right)\right\}\left(l-l^{f}\right)+h\left(1-a+\frac{a c}{b}\right) q=0 .
$$

The foreign country's policy authority maximizes its utility in a similar manner, giving rise to the condition,

$$
\left\{1+d\left(1-a+\frac{2 a c}{b}\right)\right\}\left(l^{*}-l^{* f}\right)+h\left(1-a+\frac{a c}{b}\right) q^{*}=0 .
$$

Equations (17.1), (17.2), and $w=w^{*}$ suggest $m=m^{*}$. From this relation and Equations (17.1), (9.1), (8.1), (9.8), (13.1), and (16.1), the money stock is determined as follows:

$$
\begin{aligned}
& m=m^{*}=\frac{\left\{1+d\left(1-a+2 a c^{\prime} b\right)-a h\left(1-a+a c^{\prime} b\right)\right\}(1+r / \rho) \ln \tilde{e}+h\left(1-a+a c^{\prime} b\right) a \ln a}{1+d\left(1-a+2 a c^{\prime} b\right)+h(1-a)\left(1-a+a c^{\prime} b\right)} \\
& \left(\equiv m^{N C}\right){ }^{11}
\end{aligned}
$$

According to Equation (18), the money stock in the non-cooperative regime depends on the sensitivity of migration flows to changes in real-consumption wage

\footnotetext{
${ }^{10}$ Equation (13.1) and $\partial e / \partial m=0$ imply that $\partial w / \partial m=0$, and Equation (13.2) and $\partial e^{*} / \partial m=0$ imply that $\partial w^{*} / \partial m=0$.

${ }^{11} \bar{l}=\bar{l}^{*}=\ln a$ is assumed throughout the analysis.
} 
differentials. In the non-cooperative regime, the policy authorities do not take into consideration the fact that the influence of a domestic monetary expansion for reducing unemployment via the induced fall in the effective labor force will be offset by an equal expansion abroad. Accordingly, the policy authorities unilaterally increase the money stock in order to induce migration flows and thereby to reduce unemployment. This implies that the money stock is dependent on the sensitivity of migration flows. Since policy authorities utilize migration flows to attain their policy objectives, macroeconomic interdependence through migration flows is operative in the non-cooperative regime, as pointed out by Agiomirgianakis (1998).

From Equations (9.1), (8.1), (13.1), (16.1), and (18), unemployment is derived. Equation (17.1) and unemployment give us the consumer price index.

$$
\begin{aligned}
& l-l^{f}=l^{*}-l^{* f}=\frac{h\left(1-a+a c^{\prime} b\right)\left\{-\left(1+r^{\prime} \rho\right) \ln \tilde{e}+a \ln a\right\}}{1+d\left(1-a+2 a c^{\prime} b\right)+h(1-a)\left(1-a+a c^{\prime} b\right)}\left(\equiv\left[l-l^{f}\right]^{N C}\right) . \\
& q=q^{*}=-\frac{\left\{1+d\left(1-a+2 a c^{\prime} b\right)\right\}\left\{-\left(1+r^{\prime} \rho\right) \ln \tilde{e}+a \ln a\right\}}{1+d\left(1-a+2 a c^{\prime} b\right)+h(1-a)\left(1-a+a c^{\prime} b\right)}\left(\equiv q^{N C}\right) .
\end{aligned}
$$

Equations (19) and (20) suggest that the utilities for the policy authority and the employed workers depend on the sensitivity of migration flows.

\section{Inter-government Cooperation}

This section deals with the inter-government cooperative regime where the policy authorities in the home and foreign countries behave cooperatively and the money stock, unemployment, and the consumer price index under intergovernment cooperation are determined.

Since the employed workers in the two countries behave independently and the employed workers do not cooperate with the policy authority in each country, they solve the same maximization problems as those under non-cooperation. Accordingly, the optimal effort level of the employed workers in the home country is given by Equation (16.1), and the optimal effort level of the employed workers in the foreign country is given by Equation (16.2).

Since the policy authorities in the two countries cooperate with each other, they will set their money stocks such that they maximize the sum of their utilities, treating $e$ and $e^{*}$ as given, i.e., they will solve, 
$\max _{m, m^{*}} \quad V_{P A}+V_{P A}^{*}$,

subject to (9.1), (8.1), (9.8), (9.2), (8.2), (9.9), $\partial e / \partial m=0, \partial e^{*} / \partial m=0, \partial e^{\prime} \partial m^{*}=0$, and $\partial e^{*} / \partial m^{*}=0$.

This gives us the following conditions:

$$
\begin{aligned}
& \left(1-a+\frac{a c}{b}\right) q-\frac{a c}{b} q^{*}=-\frac{1+d\left(1-a+2 a c^{\prime} b\right)}{h}\left(l-l^{f}\right)+\frac{d\left(1-a+2 a c^{\prime} b\right)}{h}\left(l^{*}-l^{* f}\right), \\
& -\frac{a c}{b} q+\left(1-a+\frac{a c}{b}\right) q^{*}=\frac{d\left(1-a+2 a c^{\prime} b\right)}{h}\left(l-l^{f}\right)-\frac{1+d\left(1-a+2 a c^{\prime} b\right)}{h}\left(l^{*}-l^{*}\right) .
\end{aligned}
$$

Equations (21.1), (21.2), and $w=w^{*}$ suggest $m=m^{*}$. From this relation and Equations (21.1), (9.1), (8.1), (9.8), (13.1), and (16.1), the money stock is determined as follows:

$$
m=m^{*}=\frac{\{1-a h(1-a)\}\left(1+r^{\prime} \rho\right) \ln \tilde{e}+h(1-a) a \ln a}{1+h(1-a)^{2}}\left(\equiv m^{I G C}\right) .
$$

According to Equation (22), in contrast to the non-cooperative regime, the money stock under inter-government cooperation does not depend on the sensitivity of migration flows to changes in real-consumption wage differentials. In the inter-government cooperative regime, the policy authorities are aware of the fact that the influence of a domestic monetary expansion for reducing unemployment via the induced fall in the effective labor force will be offset by an equal expansion abroad. Accordingly, the policy authorities do not use the monetary policies to order to induce migration flows and thereby to reduce unemployment. This suggests that the money stock is independent of the sensitivity of migration flows. Since policy authorities do not utilize migration flows to accomplish their policy objectives, macroeconomic interdependence through migration flows is not operative in the inter-government cooperative regime, as pointed out by Agiomirgianakis (1998).

Unemployment is derived from Equations (9.1), (8.1), (13.1), (16.1), and (22). Equation (21.1) and unemployment give us the consumer price index. 


$$
\begin{aligned}
& l-l^{f}=l^{*}-l^{* f}=\frac{h(1-a)\left\{-\left(1+r^{\prime} \rho\right) \ln \tilde{e}+a \ln a\right\}}{1+h(1-a)^{2}}\left(\equiv\left[l-l^{f}\right]^{I G C}\right) . \\
& q=q^{*}=-\frac{-\left(1+r^{\prime} \rho\right) \ln \tilde{e}+a \ln a}{1+h(1-a)^{2}}\left(\equiv q^{I G C}\right) .
\end{aligned}
$$

Equations (23) and (24) suggest that the utilities for the policy authority and the employed workers are independent of the sensitivity of migration flows.

\section{Comparison of the Two Regimes}

This section compares the utilities of the policy authority and the employed workers under non-cooperation and inter-government cooperation and shows which of the two regimes is advantageous to the policy authority and to the workers.

For this purpose, a special case where migration flows are sufficiently sensitive to changes in real-consumption wage differentials is considered, i.e., we take up the case where $d$ is sufficiently large.

The money stock in the non-cooperative regime for the sufficiently large sensitivity of migration flows is approximated by taking the limit of $m^{N C}$.

$$
\lim _{d \rightarrow \infty} m^{N C}=\left(1+\frac{r}{\rho}\right) \ln \tilde{e}\left(\equiv \tilde{m}^{N C}\right)
$$

A comparison of the money stocks under the two regimes for the sufficiently large sensitivity of migration flows reveals that,

$$
\tilde{m}^{N C}>\tilde{m}^{I G C}
$$

According to Equation (25), the monetary policy is more expansionary in the noncooperative regime than in the inter-government cooperative regime, provided that the sensitivity of migration flows is sufficiently large. This is because, as mentioned above, in the non-cooperative regime, the policy authorities increase the money stock in an attempt to reduce unemployment. Moreover, the money stock becomes larger with increases in the sensitivity of migration flows $\left(\partial m^{N C} / \partial d>0\right)$. In contrast, in the inter-government cooperative regime, as mentioned in the previous section, the money stock is independent of the sensitivity of migration 
flows. $^{12}$

In the non-cooperative regime, unemployment decreases while the consumer price index increases as the migration flows become more sensitive $\left.\left(\left(\partial l-l^{f}\right]^{N C} / \partial d>0, \partial q^{N C} / \partial d>0\right)\right)$. This is because the larger sensitivity of migration flows renders the monetary expansion more effective in reducing unemployment, and a larger money stock results in an increase in the consumer price index (see Equation 9.8). On the other hand, in the inter-government cooperative regime, the unemployment and the consumer price index are independent of the sensitivity of migration flows (see Equations 23 and 24).

Accordingly, in case of sufficiently large sensitivity of migration flows, unemployment is lower under non-cooperation than under inter-government cooperation, i.e., $\lim _{d \rightarrow \infty}\left[l-l^{f}\right]^{N C}>\left[l-l^{f}\right]^{I G C}$, leading to a higher utility for the policy authority in the non-cooperative regime, while the consumer price index is higher under non-cooperation than under inter-government cooperation, i.e., $\lim _{d \rightarrow \infty} q^{N C}>q^{I G C}$, leading to a lower utility for the policy authority in the non-cooperative regime.

Since the latter negative effects dominate the former positive effects, the utility for the policy authority in the inter-government cooperative regime is higher than that in the non-cooperative regime, i.e., $V_{P A}^{G G C}>V_{P A}^{N C}$, provided that the sensitivity of the migration flows is sufficiently large. ${ }^{13}$ In other words, inter-government cooperation may prove to be advantageous to the policy authority. This result is the same as the one derived by Agiomirgianakis (1998).

Substituting Equations (9.8) and (9.9) into Equations (14.1) and (14.2), respectively, the expected lifetime utility of the employed workers can be expressed as,

$$
V_{E}=V_{E}^{*}=-\frac{(1-a) m+a w-a \ln a}{r}+\frac{\ln \tilde{e}}{\rho} .
$$

\footnotetext{
${ }^{12}$ If we do not assume migration, monetary policies become more expansionary under inter-government cooperation than under non-cooperation, i.e., $m^{I G C}>\left.m^{N C}\right|_{d=0}$. This is the result by Rogoff (1985). Accordingly, international migration changes the ranking of the money stocks under the two regimes.

${ }^{13}$ If we do not assume migration, the smaller money stock makes unemployment higher under noncooperation than under inter-government cooperation, leading to a lower policy authority's utility in the non-cooperative regime, whereas it makes the consumer price index lower under non-cooperation than under inter-government cooperation, leading to a higher policy authority's utility in the noncooperative regime. Since the former negative effects dominate the latter positive effects, the policy authority's utility is higher in the inter-government regime than in the non-cooperative regime, i.e., $V_{P A}^{I G C}>\left.V_{P A}^{N C}\right|_{d=0}$. This suggests that international migration does not change the ranking of the policy authority's utilities under the two regimes.
} 
Since nominal wages and effort do not differ across regimes, the above equation suggests that the expected lifetime utility of the employed workers decreases with increases in the money stock. Therefore, using Equation (25), we can derive the result that the expected lifetime utility of the employed workers in the intergovernment cooperative regime is higher than that in the non-cooperative regime, i.e., $V_{E}^{I G C}>V_{E}^{N C}$, provided that the sensitivity of the migration flows is sufficiently large. ${ }^{14}$ In other words, inter-government cooperation may prove to be advantageous to the employed workers.

Inter-government cooperation may also prove to be advantageous to the unemployed workers. This is because the larger money stock under non-cooperation makes the consumer price index higher, leading to the lower expected lifetime utility of a representative unemployed worker under non-cooperation, i.e., $V_{U}^{I G C}>V_{U}^{N C}$. Therefore, inter-government cooperation may prove to be advantageous to all workers.

This result is different from the one derived by Agiomirgianakis (1998). In his model, wages are determined by the negotiations between the firm and the labor union, and the labor union's utility takes the same value in the two regimes. ${ }^{15}$

Results derived from the comparison of the utilities of the policy authority and the workers in the two regimes can be summarized as follows: Inter-government cooperation may prove to be advantageous not only to the policy authority but also to the workers, provided that the workers migrate between two countries, and in each country, nominal wages are determined by the efficiency wage hypothesis.

\section{Conclusions}

Using a symmetric two-country macroeconomic model with international migration and efficiency wages, the utilities of the policy authority and the workers in the non-cooperative and inter-government cooperative regimes were compared, and inter-government cooperation was found to be advantageous not only to the policy authority but also to the workers if migration flows are sufficiently sensitive to changes in real-consumption wage differentials. ${ }^{16}$

\footnotetext{
${ }^{14}$ Since, as mentioned already, under the assumption of no migration, the money stock is larger in the inter-government cooperative regime than in the non-cooperative regime, the expected lifetime utility of the employed workers is higher in the non-cooperation regime than in the inter-government cooperative regime, i.e., $\left.V_{E}^{N C}\right|_{d=0}>V_{E}^{I G C}$. Accordingly, international migration changes the ranking of the employed workers' expected lifetime utilities under the two regimes.
}

${ }^{15}$ See Agiomirgianakis (1998) p.260 for the equality of the labor union's utility under the two regimes. 
Although this result is different from that derived by Agiomirgianakis (1998), it is in agreement with his argument that international migration of labor alters the nature of monetary policy games played by monetary authorities in interdependent economies.

This paper's result suggests that inter-government cooperation appears to be compatible with open economies that are characterized by migration and efficiency wages.

\section{Acknowledgements}

I am deeply indebted to George M. Agiomirgianakis for providing many encouraging comments and helpful suggestions. This paper was presented at the 4th annual meeting of the European Economics and Finance Society. I am grateful to the participants at the conference for helpful comments and valuable suggestions. Of course, any shortcomings of the paper are my responsibility.

Received 17 May 2005, Accepted 31 July 2006

\section{References}

Agiomirgianakis, G. M. (1996), International Macroeconomic Interdependence and International Migration of Labour, International Journal of Finance and Economics, 1, 133-147.

Agiomirgianakis, G. M. (1998), Monetary Policy Games and International Migration of Labor in Interdependent Economies, Journal of Macroeconomics, 20, 243-266.

Agiomirgianakis, G. M. (1999), The Macroeconomics of Open Economies under Labor Mobility, Ashgate, Aldershot.

Agiomirgianakis, G. M. (2000), Monetary Policy Games and International Migration in a Small Open Economy, Review of International Economics, 8, 698-711.

Agiomirgianakis, G. M. and Zervoyianni, A. (2001), Macroeconomic Equilibrium with Illegal Immigration." Economic Modelling, 18, 181-202.

Carter, T. J. (1998), Policy in a Two-Sector Efficiency Wage Model: Substituting Good Jobs for Bad, Journal of Post Keynesian Economics, 20, 445-461.

Carter, T. J. (1999), Illegal Immigration in an Efficiency Wage Model, Journal of Interna-

\footnotetext{
${ }^{16}$ This result does not directly imply that the monetary union may prove to be advantageous to the policy authority and to the workers, since, even under inter-government cooperation, two independent monetary authorities are being assumed. However, it seems very interesting to examine the case of a single monetary authority.
} 
tional Economics, 49, 385-401.

Dunlop, J. T. (1944), Wage Determination under Trade Unions. New York Macmillan.

Hamada, K. (1976), A Strategic Analysis of Monetary Interdependence, Journal of Political Economy, 84, 677-700.

Jensen, H. (1993), International Monetary Policy Cooperation in Economies with Centralized Wage Setting, Open Economies Review, 4, 269-285.

Müller, T. (2003), Migration Policy in a Small Open Economy with a Dual Labor Market, Review of International Economics, 11, 130-143.

Oswald, A. J. (1985), The Economic Theory of Trade Unions: An Introductory Survey, Scandinavian Journal of Economics, 87, 160-193.

Rogoff, K. (1985), Can International Monetary Cooperation be Counterproductive? Journal of International Economics, 18, 199-217.

Shapiro, C. and Stiglitz, J. E. (1984), Equilibrium Unemployment as a Worker Discipline Device, American Economic Review, 74, 433-444.

Shimada, A. (2003), Kokusai rodo ido no makurokeizaigaku bunseki (Macroeconomic Analysis of International Migration of Labor), Gogensha, Tokyo.

Shimada, A. (2004), Reducing the Inflow of Unskilled Foreign Workers, South-Eastern Europe Journal of Economics, 2, 85-96.

Zervoyianni, A. (1997), Monetary Policy Games and Coalitions in a Two-Country Model with Unionised Wage Setting, Oxford Economic Papers, 49, 57-76. 